\title{
Northern winter stratospheric temperature and ozone responses to ENSO inferred from an ensemble of Chemistry Climate Models
}

\author{
C. Cagnazzo ${ }^{1}$, E. Manzini ${ }^{1,2}$, N. Calvo ${ }^{3}$, A. Douglass ${ }^{4}$, H. Akiyoshi ${ }^{5}$, S. Bekki ${ }^{6}$, M. Chipperfield ${ }^{7}$, M. Dameris ${ }^{8}$, \\ M. Deushi ${ }^{9}$, A. M. Fischer ${ }^{10,}{ }^{*}$, H. Garny ${ }^{8}$, A. Gettelman ${ }^{11}$, M. A. Giorgetta ${ }^{12}$, D. Plummer $^{13}$, E. Rozanov $^{10,15}$, \\ T. G. Shepherd ${ }^{14}$, K. Shibata ${ }^{9}$, A. Stenke ${ }^{8}$, H. Struthers ${ }^{16, * *}$, and W. Tian ${ }^{7}$ \\ ${ }^{1}$ Centro Euro-Mediterraneo per i Cambiamenti Climatici, Bologna, Italy \\ ${ }^{2}$ Istituto Nazionale di Geofisica e Vulcanologia, Bologna, Italy \\ ${ }^{3}$ Dpto. Fisica de la Tierra II, Universidad Complutense de Madrid, Spain \\ ${ }^{4}$ NASA Goddard Space Flight Center, Greenbelt MD, USA \\ ${ }^{5}$ National Institute for Environmental Studies, Tsukuba, Japan \\ ${ }^{6}$ Service d'Aeronomie du CNRS, IPSL, Paris, France \\ ${ }^{7}$ School of Earth and Environment, University of Leeds, Leeds, UK \\ ${ }^{8}$ DLR-Institut für Physik der Atmosphäre, Oberpfaffenhofen, Germany \\ ${ }^{9}$ Meteorological Research Institute, Tsukuba, Ibaraki 305-0052, Japan \\ ${ }^{10}$ Institute for Atmospheric and Climate Science, ETH Zürich, Zürich, Switzerland \\ ${ }^{11}$ National Center for Atmospheric Research, Boulder, Colorado, USA \\ ${ }^{12}$ Max Planck Institute for Meteorology, Hamburg, Germany \\ ${ }^{13}$ Environment Canada, Toronto, Ontario, Canada \\ ${ }^{14}$ Department of Physics, University of Toronto, Toronto, Ontario, Canada \\ ${ }^{15}$ Physical-Meteorological Observatory/World Radiation Center, Davos, Switzerland \\ ${ }^{16}$ National Institute of Water \& Atmospheric Research, Auckland, New Zealand \\ *now at: Federal Office of Meteorology and Climatology MeteoSwiss, Zürich, Switzerland \\ ** now at: ITM - Stockholms universitet, Stockholms, Sweden
}

Received: 10 April 2009 - Published in Atmos. Chem. Phys. Discuss.: 15 May 2009

Revised: 19 November 2009 - Accepted: 20 November 2009 - Published: 27 November 2009

\begin{abstract}
The connection between the El Niño Southern Oscillation (ENSO) and the Northern polar stratosphere has been established from observations and atmospheric modeling. Here a systematic inter-comparison of the sensitivity of the modeled stratosphere to ENSO in Chemistry Climate Models (CCMs) is reported. This work uses results from a number of the CCMs included in the 2006 ozone assessment. In the lower stratosphere, the mean of all model simulations reports a warming of the polar vortex during strong ENSO events in February-March, consistent with but smaller than the estimate from satellite observations and ERA40 reanalysis. The anomalous warming is associated with an anomalous dynamical increase of column ozone north of $70^{\circ} \mathrm{N}$ that is accompanied by coherent column ozone decrease in the
\end{abstract}

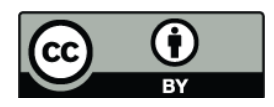

Correspondence to: C. Cagnazzo (chiara.cagnazzo@cmcc.it)
Tropics, in agreement with that deduced from the NIWA column ozone database, implying an increased residual circulation in the mean of all model simulations during ENSO. The spread in the model responses is partly due to the large internal stratospheric variability and it is shown that it crucially depends on the representation of the tropospheric ENSO teleconnection in the models.

\section{Introduction}

The El Niño Southern Oscillation (ENSO) is a tropical atmosphere-ocean phenomenon and a source of large-scale climate variability for the atmosphere - ocean system. During boreal winter, the typical teleconnection between the warm phases of ENSO and the mid-latitude North Pacific region (Hoerling et al., 1997; Strauss and Shukla, 2000 among others) can favour the enhancement of mid-latitude planetary

Published by Copernicus Publications on behalf of the European Geosciences Union. 
waves and consequently their upward propagation into the stratosphere (Manzini et al., 2006). Due to this increase in extra-tropical stratospheric planetary wave activity, warm ENSO events have been found to be associated with anomalous warming and anomalously high geopotential height in the polar stratosphere, both from observations (van Loon and Labitzke, 1987; Hamilton, 1993; Camp and Tung, 2007; Garfinkel and Hartmann, 2007) and comprehensive modeling of the troposphere-stratosphere system (Sassi et al., 2004; Taguchi and Hartmann, 2006; Manzini et al., 2006; Garcia-Herrera et al., 2006). Recently, the warm ENSO signal in the Arctic has also been found in radiosonde data (Free and Seidel, 2009). At high Northern latitudes, large zonal mean anomalies, in temperature and zonal wind, associated with the warm phase of ENSO appear in the upper stratosphere in early winter and then propagate downwards to the lower stratosphere on monthly time scales through wave mean flow interaction (Manzini et al., 2006). The modeling work of Manzini et al. (2006) has shown that these zonal mean anomalies associated with ENSO occur also in the troposphere in late winter and spring, and the subsequent modeling work of Cagnazzo and Manzini (2009) has shown that they are implicated in the surface teleconnection between ENSO and the North European region.

Given that the reported polar warming associated with warm ENSO events is a manifestation of an enhanced Brewer-Dobson circulation, more ozone should be transported from the source region in the tropics toward high polar latitudes during warm ENSO events. In fact, interannual variations in column ozone and temperature in the northern polar stratosphere are linked to planetary scale wave activity (Fusco and Salby, 1999; Randel et al., 2002; Weber et al., 2003). At Arctic and mid-latitude sites, an anomalous accumulation of column ozone was indeed reported for the strong and long lasting 1940-1942 ENSO event by Brönnimann et al. (2004). In the tropics, a signal in stratospheric ozone has been reported from the SAGE II satellite dataset (Randel et al., 2009). Consistently with the ENSO signal in ozone, Randel et al. (2009) and the independent work of Free and Seidel (2009) report also an ENSO signal in the tropical lower stratosphere temperature.

The response to ENSO has also been analysed in a few Chemistry Climate Models (Fischer et al., 2008; Steinbrecht et al., 2006, Brönnimann et al., 2006; Garny et al., 2009; Randel et al., 2009) and in a chemical transport model (Sassi et al., 2004).

The purpose of this work is to extend these previous studies that analyzed the ENSO response in Chemistry Climate Models (CCMs), by systematically evaluating the response to warm ENSO in the pool of simulations for the recent past performed with the CCMs participating in the ChemistryClimate Model Validation Activity (CCMVal-1) of SPARC that are discussed in Eyring et al. (2006). Many of these models contributed to the 2006 ozone assessment (WMO/UNEP, 2007). These simulations have been performed with pre- scribed observed sea surface temperatures (SSTs), and therefore include the ENSO forcing on the modeled atmosphere. However, the manifestation of the ENSO effect on the stratosphere depends also on the ENSO teleconnection in the troposphere, not necessarily similarly represented in the CCMs. Another aspect obscuring the ENSO signal in the stratosphere is the typical high variability of the boreal winter stratosphere.

The focus of this work is on the Northern polar stratosphere temperature and ozone response during boreal winter, for the 1980-1999 period. Specifically, we aim at identifying any coherence in the temperature and ozone responses across the Chemistry Climate Models. This in turn may provide some insight into understanding the causes of the range of responses, in terms of interannual variability and model biases.

Note that the cold ENSO events that occurred in the 19801999 period have been found to have negligible influence on the Northern polar stratosphere during winter (Manzini et al., 2006; see also Sassi et al., 2004), and therefore are not considered in this work. The negligible response may be partly due to the smaller SST anomalies that occurred for cold events during the period considered here. This apparent little sensitivity of the Arctic stratosphere to cold ENSO derived from model results is consistent with the recent analysis of radiosonde temperature data by Free and Seidel (2009).

\section{Datasets and methodology}

\subsection{Models}

The CCM datasets used in this work result from transient runs aimed at reproducing the time period of 1980-1999 (Eyring et al., 2006): most of the simulations include anthropogenic and natural forcings based on changes in SSTs, trace gases, solar variability, and aerosol effects (from major volcanic eruptions). The models are summarized and referenced in Table 1. The description of the external forcings can be found in Table 2 of Eyring et al. (2006).

Modeled monthly zonal mean temperature and column ozone and (when available) monthly three-dimensional geopotential height fields have been analyzed. AMTRAC, CCSRNIES, MRI, SOCOL and WACCM models have provided a set of 3, 3, 5, 9 and 3 realizations (i.e., they have repeated the simulation of the 1980-1999 period with different meteorological initial conditions), respectively. SOCOL, E39C-A and MRI models have provided outputs from updated model versions with respect to those described in Eyring et al. (2006). The analysis on the AMTRAC, GEOSCCM, and 2 members of CCSRNIES simulations is restricted to the zonal mean fields, because threedimensional fields were not available for these cases. 


\subsection{Observations and Reanalysis Data}

Three datasets covering the 1980-1999 period, are considered:

1. Time series of monthly mean temperature and geopotential height from the European Centre for MediumRange Weather Forecast Re-Analysis (ERA-40, Uppala et al., 2005; Uppala et al., 2004).

2. Stratospheric Sounding Unit (SSU) temperatures (Nash and Edge, 1989; Brindley et al., 1999) and Microwave Sounding Unit (MSU) temperatures (Spencer and Christy, 1995). These datasets consist of zonal temperature anomalies every 10 degrees from $70^{\circ} \mathrm{S}$ to $70^{\circ} \mathrm{N}$ for the $3 \mathrm{SSU}$ channels (anomalies peaking at 15 , 6 , and $2 \mathrm{hPa}$ ) and 4 synthetic channels (peaking at 50, 20, 5, 1.5 and $0.5 \mathrm{hPa}$, Nash and Edge, 1989) and for the MSU channel $(90 \mathrm{hPa})$.

3. NIWA column ozone dataset, which combines data from several United States and European satellites with a global set of ground stations (Bodeker et al., 2005).

\subsection{Diagnostics}

Composites for the period 1980-1999 are constructed for temperature, column ozone and eddy geopotential height fields. For each month of the extended winter season (October to April), warm ENSO and NEUTRAL composites of monthly means are considered, for the models and the datasets. Our standard warm ENSO composite is made up of the 4 largest warm events that occurred in the period 1980-1999 (hereafter 4 WE), see Table 2 for the list of the events. The events are selected on the basis of the SST anomaly averaged from January to March in the Nino-3 region from the National Centers for Environmental Prediction (NCEP)/Climate Prediction Center (CPC) (http://www. cpc.ncep.noaa.gov/data/indices). These four events are those typically studied in climate research on ENSO teleconnections, for example Strauss and Shukla (2000) and Manzini et al. (2006). Following Manzini et al. (2006), the NEUTRAL composite is made of the years within the 1980-1999 period, that exclude these warm ENSO events as well as the 4 largest cold ENSO events (see Table 2). Two of the four winters considered in the warm ENSO composite analysis were disturbed by volcanic eruptions (1982-1983 and 19911992). Intense volcanic eruptions are believed to cause on average a cooling and a strengthening of the vortex (Labitzke and Van Loon, 1989) possibly leading to a distortion of the anomaly associated with ENSO in the polar stratosphere. For this reason, a second warm ENSO composite has been constructed, including two additional ENSO events (hereafter $6 \mathrm{WE}$, see Table 2), with the two additional events not disturbed by the volcanic external forcing, albeit characterized by weaker ENSO phenomena.
Table 1. List of the models used in this work.

\begin{tabular}{|c|c|}
\hline AMTRAC (3) & $\begin{array}{l}\text { Austin et al. (2006) } \\
\text { Austin and Wilson (2006) }\end{array}$ \\
\hline \multirow[t]{3}{*}{ CCSRNIES (3) } & Akiyoshi et al. (2004) \\
\hline & Kurokawa et al. (2005) \\
\hline & Akiyoshi et al. (2009) \\
\hline \multirow[t]{3}{*}{ CMAM } & Beagley et al. (1997) \\
\hline & de Grandpré et al. (2000) \\
\hline & Scinocca et al. (2008) \\
\hline \multirow[t]{2}{*}{ E39C-A } & Stenke et al. (2009) \\
\hline & Garny et al. (2009) \\
\hline \multirow[t]{2}{*}{ GEOSCCM } & Bloom et al. (2005) \\
\hline & Stolarski et al. (2006) \\
\hline LMDZrepro & Lefevre et al. (1994) \\
\hline \multirow[t]{2}{*}{ MAECHAM4CHEM } & Manzini et al. (2003) \\
\hline & Steil et al. (2003) \\
\hline MRI (5) & Shibata and Deushi $(2008 a, b)$ \\
\hline \multirow[t]{2}{*}{ SOCOL (9) } & Egorova et al. (2005) \\
\hline & Rozanov et al. (2005) \\
\hline \multirow[t]{3}{*}{ UMETRAC } & Austin (2002) \\
\hline & Austin and Butchart (2003) \\
\hline & Struthers et al. (2004) \\
\hline UMSLIMCAT & Tian and Chipperfield (2005) \\
\hline WACCM (3) & Garcia et al. (2007) \\
\hline
\end{tabular}

As discussed for volcanic eruptions, the QBO and solar cycle are sources of variability for the stratosphere and their non-linear interaction with the ENSO signal could interfere with the stratospheric response to ENSO (e.g. Garfinkel and Hartmann, 2007). As mentioned in Sect. 2.1, most of the CCMVal simulations include these signals. To investigate these connections in beyond the scope of this work, therefore the modeled stratospheric response to ENSO has not been stratified separating model simulations with and without one (or more) of these signals, an approach that would require a much larger ensemble of simulations.

For every field considered, "ENSO anomalies" are defined as the difference between the warm ENSO composite and the NEUTRAL composite.

In order to compactly compare the response of each model to the ENSO forcing, the following 4 indices are defined and calculated from the ENSO anomalies:

$\Delta \boldsymbol{T}$ index, defined as the February-March, polar cap $\left(70^{\circ} \mathrm{N}-90^{\circ} \mathrm{N}\right)$ and $30-70 \mathrm{hPa}$ average of the ENSO zonal mean temperature anomaly $(<T>$ ENSO $-<T>$ NEUTRAL $)$. This index represents the temperature anomaly associated to ENSO in the lower stratosphere at the end of winter/beginning of spring.

$\boldsymbol{\Delta} \boldsymbol{Z}$ index. The known tropospheric teleconnection of ENSO with Northern midlatitude stationary waves in December-January-February (DJF) consists of an eastward elongation of the North Pacific trough (Hoerling et al., 1997; 
Table 2. Warm ENSO, cold ENSO and NEUTRAL years (year index for January) for 4 WE and 6 WE.

\begin{tabular}{lll}
\hline & 4 WE & 6 WE \\
\hline Warm & $1983,1987,1992,1998$ & $1983,1987,1988,1992,1995,1998$ \\
Cold & $1985,1989,1996,1999$ & $1985,1989,1996,1999$ \\
NEUTRAL & $1981,1982,1984,1986,1988,1990,1991,1993,1994,1995,1997$ & $1981,1982,1984,1986,1990,1991,1993,1994,1997$ \\
\hline
\end{tabular}

see their Fig. 6). In order to quantify this typical tropospheric pattern and to evaluate the troposphere of the models, we defined the $\Delta Z$ index in the following way: At $50^{\circ} \mathrm{N}$ and $500 \mathrm{hPa}$, for the DJF average: (1) The difference between the warm ENSO and the NEUTRAL ENSO composites, of the stationary eddy geopotential height is computed and defined to be the tropospheric stationary wave anomaly. (2) The minimum value of the tropospheric stationary wave anomaly between 180 and 360 longitude is searched and found. (3) This minimum value is smoothed by an average over $10 \%$ of its value. (4) The smoothed minimum of the tropospheric stationary wave anomaly multiplied by -1 is the $\Delta Z$ index. The link between this index and the eddy heat flux at $100 \mathrm{hPa}$ is discussed in the Appendix A.

$\Delta \mathbf{O}_{3}$ index, defined as the February-March, polar cap $\left(70^{\circ} \mathrm{N}-90^{\circ} \mathrm{N}\right)$ average of the ENSO zonal mean column ozone anomaly ( $\left.<\mathrm{O}_{3}>_{\text {ENSO }}-<\mathrm{O}_{3}>_{\text {NEUTRAL }}\right)$. This index is aimed at quantifying the column ozone anomaly associated to the ENSO teleconnection in February and March in the polar region only.

$\Delta \mathbf{O}_{\mathbf{3}}(\mathbf{F M}-\mathbf{N D})$ index, defined as the February-March mean minus the November-December mean of an area average of the ENSO zonal mean column ozone anomaly. This index has been calculated for the polar cap $\left(70^{\circ} \mathrm{N}-90^{\circ} \mathrm{N}\right)$ and the tropics $\left(15^{\circ} \mathrm{S}-15^{\circ} \mathrm{N}\right)\left(\left(<\mathrm{O}_{3}(\mathrm{FM})>-<\mathrm{O}_{3}(\mathrm{ND})>\right.\right.$ )$\left._{\text {ENSO }}-\left(<\mathrm{O}_{3}(\mathrm{FM})>-<\mathrm{O}_{3}(\mathrm{ND})>\right)_{\text {NEUTRAL }}\right)$ and it represents the wintertime increase/decrease in the ENSO zonal mean column ozone anomaly at polar/tropical latitudes. Salby and Callaghan (2002) have shown that it is the tendency (i.e. the anomalous wintertime increase of column ozone at high latitudes) that is coupled to the residual circulation.

\section{Temperature in the lower stratosphere}

Figure 1 shows the time evolution from October to April of the ENSO zonal mean temperature anomalies at $70^{\circ} \mathrm{N}$, from $100 \mathrm{hPa}$ to $0.1 \mathrm{hPa}$, for the composite of the 4 warm events (top) and the 6 warm events (bottom), for both the SSU/MSU (left) and ERA40 (right) data. Figure 1 shows that in the case of the 4 largest ENSO events, the polar warming occurs first in the upper stratosphere (about $4 \mathrm{~K}$ for SSU and $8 \mathrm{~K}$ for ERA40, significant in December at 95\%) and then descends to the lower stratosphere, characteristic of the polar night jet variability (Kuroda and Kodera, 2001). The warming is about $4 \mathrm{~K}$ between 50 and $100 \mathrm{hPa}$ significant in January and February at $90 \%$ for SSU/MSU, and reaching $95 \%$ in ERA40. In the upper stratosphere, the cooling above the warming may be a manifestation of a large-scale dynamical response involving the circulation in the mesosphere. Figure 1 also shows that the warming associated to ENSO is reduced when considering the 6 largest ENSO events $(4 \mathrm{~K}$ between 10 and $1 \mathrm{hPa} ; 2 \mathrm{~K}$ in the lower stratosphere for SSU/MSU; $6 \mathrm{~K}$ between 10 and $1 \mathrm{hPa} ; 2 \mathrm{~K}$ in the lower stratosphere for ERA40; the signal is significant at $95 \%$ in the upper stratosphere and not significant in the lower stratosphere for both the datasets). This result is consistent with the fact that ENSO is weaker for the two additional cases. Therefore, the response is reduced and less significant due to the internal variability of the Northern polar stratosphere. Figure 1 also shows that the temperature response at $70^{\circ} \mathrm{N}$ in December, January and February is the same for ERA40 and SSU/MSU below $20 \mathrm{hPa}$, but it is about double for ERA40 above this level. These results are in agreement with observational studies, in particular with Camp and Tung (2007) who applied a linear discriminant analysis on 47 years of NCEP stratospheric temperature (10$50 \mathrm{hPa}$ ) and found that the warm-ENSO years are $4 \mathrm{~K}$ significantly warmer. In the upper stratosphere the ENSO anomalies derived from the ERA-40 data have also been found to be larger than those derived from the NCEP/CPC (Manzini et al., 2006). In our analysis we will focus on the region between $30 \mathrm{hPa}$ and $70 \mathrm{hPa}$.

Because we are interested in changes that might be relevant for ozone, we summarize the reporting of the model response to ENSO by plotting the time evolution from October to April of the zonal mean temperature response to ENSO in the lower stratosphere $(30-70 \mathrm{hPa})$ over the polar cap $\left(70^{\circ} \mathrm{N}-90^{\circ} \mathrm{N}\right)$ as shown in Fig. 2. The results from ERA40 and SSU shown in Fig. 2 reproduce those deduced from Fig. 1. In Fig. 2 (left), one curve per model is plotted, i.e. the anomaly has been averaged over the set of multiple realizations performed by the same model, when available, in order to reduce the number of lines in the plot. In the right panels of Fig. 2 we estimate the response to ENSO, by computing the mean of all simulations and its significance, the latter estimated with a t-Student test performed over the total number (30) of available simulations.

For the $4 \mathrm{WE}$ anomaly (Fig. 2 top-right), the largest temperature warming is obtained in February (about $7 \mathrm{~K}$ for 

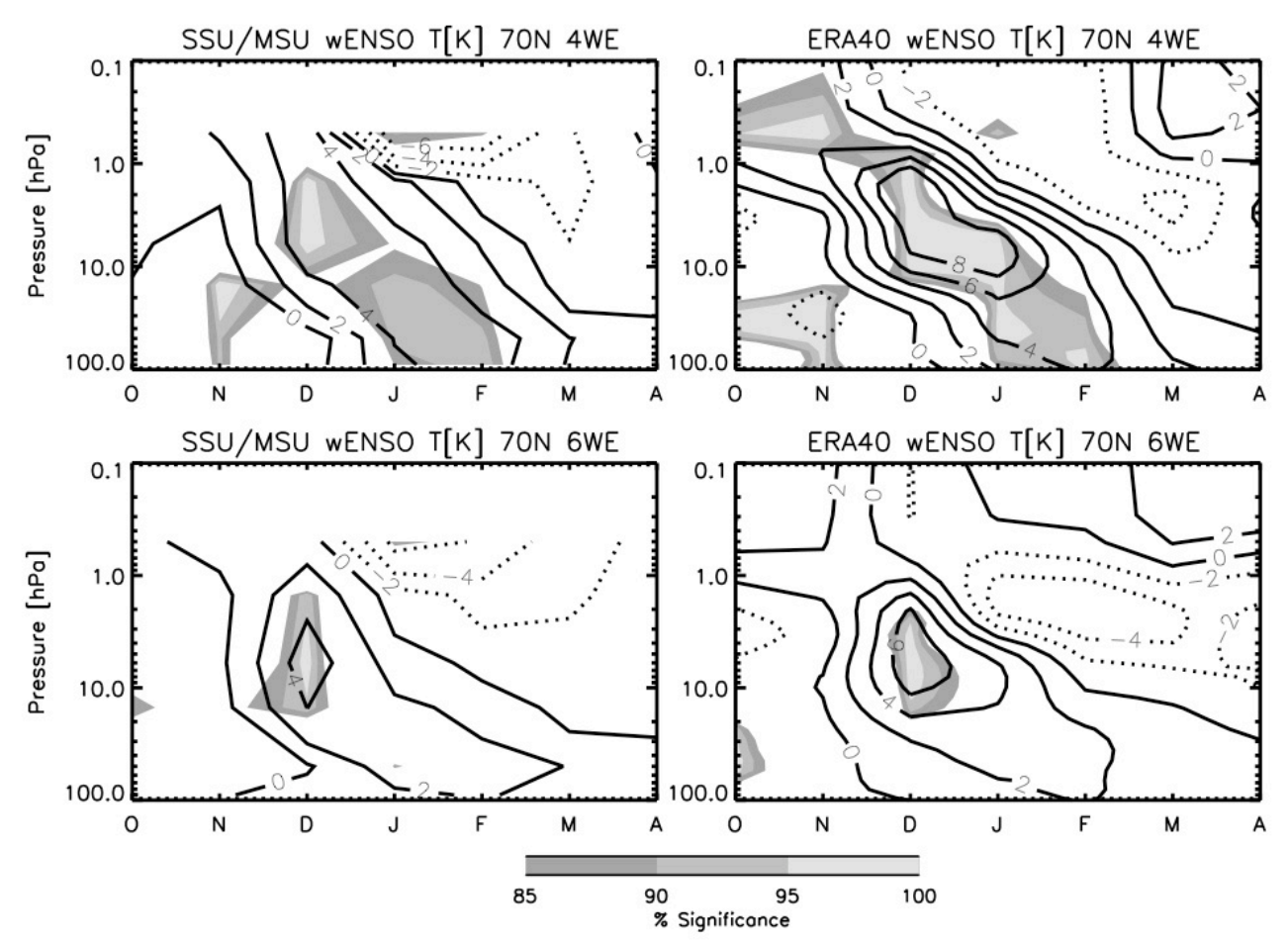

Fig. 1. Monthly zonal mean temperature ENSO anomalies (ENSO minus NEUTRAL composites) from October to April at $70^{\circ} \mathrm{N}$ in zonal mean temperature for (left) the MSU4/SSU satellite and (right) ERA40 reanalysis, considering (top) the 4 and (bottom) the 6 major events from 1980 to 1999 . Horizontal bar reports grey shadings showing the significance levels. Contour interval: $2 \mathrm{~K}$, dotted lines represent negative values.

ERA40 and $5.5 \mathrm{~K}$ in SSU), whereas for the mean of all model simulations the largest warming is found in March $(2.8 \mathrm{~K}$, significant at $95 \%$ ). The mean of all model simulations is positive and significant in February (2 K, significant at 90\%) and in April (1.8 K, significant at 90\%). The warming for the mean of all model simulations in late winter and spring is relatively small compared with the reanalysis and satellite data, because the models show quite variable responses (see the spread of the colored curves on Fig. 2, left). For some models, the largest positive anomaly at these altitudes is found in January or even in March-April; for three of them the positive anomaly is greater than SSU, but lower than ERA40; and three models do not show any warming in this layer. Bearing in mind the internal stratospheric variability, we can conclude that the ERA40, SSU and the model results are consistent and agree within the uncertainties. Associated with this stratospheric warming, a weakening of the polar vortex is found, that is highly variable across the models (not shown). The zonal mean temperature response to ENSO in the tropical lower stratosphere (not shown) reports a cooling of about $-1 \mathrm{~K}$ in February and $-0.5 \mathrm{~K}$ in March for ERA40. About half of this cooling is reproduced by the mean of all model simulations.
The analysis of Figs. 1 and 2 shows that the time evolution of the temperature anomaly for the 6 warm ENSO events, with the two additional events not disturbed by the volcanic external forcing, is similar but slightly weaker than the anomaly for the 4 largest ENSO events for the model mean. From here on the analysis will focus on the 4 warm ENSO composite only.

\section{Troposphere teleconnection and link to the response in the stratosphere}

In order to relate the modeled response in the polar lower stratosphere to the representation of the ENSO teleconnections within the troposphere (specifically, in the mid-latitude North Pacific region), the relationship between the $\Delta Z$ index (see Sect. 2), measure of the ENSO tropospheric teleconnection, and the $\Delta T$ index, measure of February-March polar lower stratosphere temperature anomaly, is shown in Fig. 3 (the $\Delta Z$ index has been calculated for 24 of the 30 simulations).

The $\Delta T$ index distribution across the simulations tends to be positive (Fig. 3, top-left): 18 simulations show positive response, 6 simulations a negative response, with the largest occurrence in the positive anomaly associated to the 2-3 K bin. These results summarize Fig. 2. The distribution 
4 WARM EVENTS

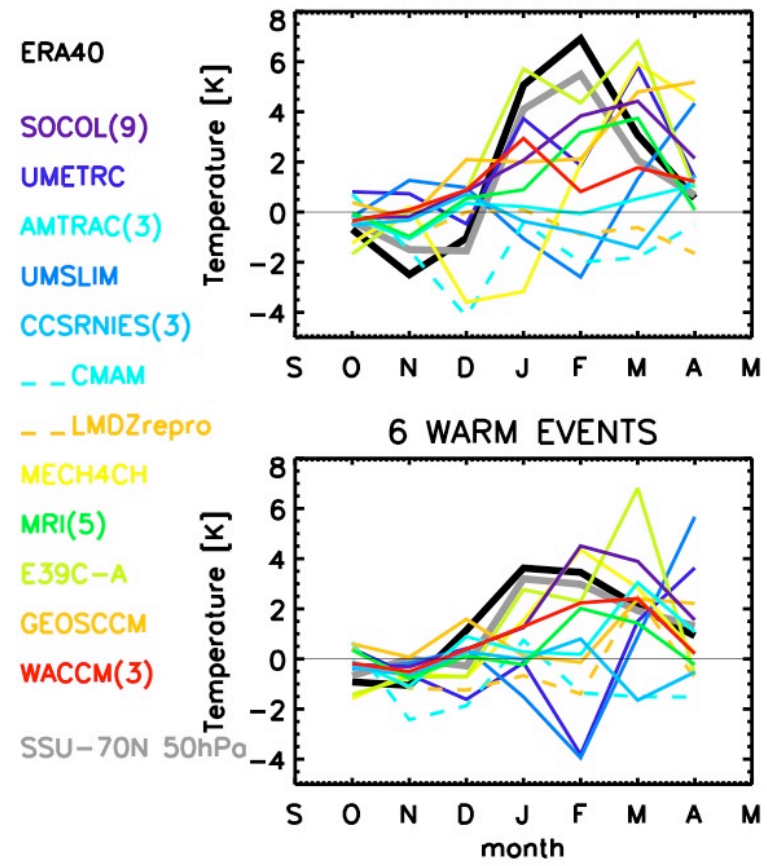

4 WARM EVENTS

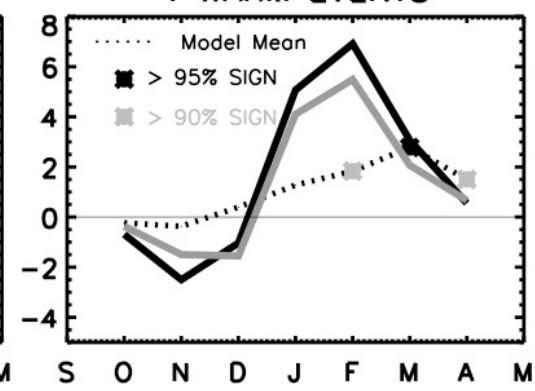

6 WARM EVENTS

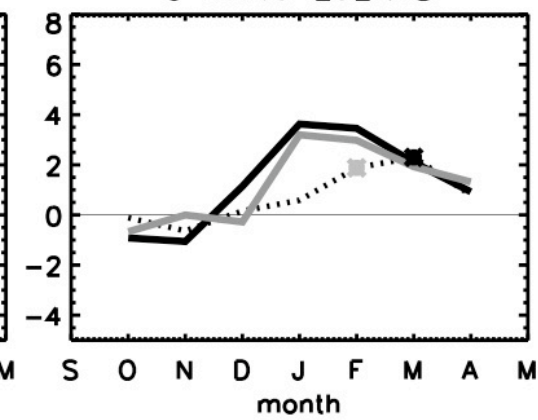

Fig. 2. (Left) Monthly zonal mean temperature ENSO anomalies from October to April, averaged over the polar cap $\left(70^{\circ} \mathrm{N}-90^{\circ} \mathrm{N}\right)$ and the $\left(30-70 \mathrm{hPa}\right.$ ) pressure band, for each model, ERA40 (black thick line) and SSU (grey thick line). SSU anomalies are calculated at $70^{\circ} \mathrm{N}$ and $50 \mathrm{hPa}$. Concerning the simulations (colored lines), one curve per model is plotted, i.e. the anomaly has been averaged over the ensemble members, when available. (Right) the mean of all simulations calculated over the 30 models (dotted line) and, repeated from the left panel, ERA40 (black thick line) and SSU (grey thick line). Superimposed are significances at more than 90\% (grey stars) and 95\% (black stars) for the model mean. (Top) 4 ENSO events and (bottom) 6 ENSO events.

of the $\Delta Z$ index across the simulations (shown in Fig. 3 bottom-right) indicates that the response is variable also for this index. This index is a quantitative estimate of the tropospheric stationary wave anomaly during strong ENSO episodes. Consequently, a large value of this index can imply an increase of vertically propagating planetary waves emerging from the troposphere (see the Appendix A for an example).

The maximum occurrence for this index for the model data pool is found in the $40-55 \mathrm{~m}$ bin whereas the $\Delta Z$ index for ERA40 is larger $(103 \mathrm{~m})$. In Fig. 3 top-right are shown the 1-standard deviation and 2-standard deviations for the $\Delta Z$ index of ERA40 (the vertical continuous and dotted lines, respectively); note that the maximum occurrence of the $\Delta Z$ index for the model simulations is close to the 2-sigma value of ERA40. The $\Delta Z$ index for ERA40 is about four times its standard deviation, whereas for the majority of the model simulations the ratio of this index with respect to its standard deviation is smaller (about 3, not shown). This result shows that the ENSO tropospheric stationary wave anomalies are larger (and with higher variability) for ERA40 than for the majority of the simulations (note that ERA40 is dominated by the large 1998 ENSO event, not shown). This discussion implies that the ENSO extratropical response in the eddy geopotential height field is robust for ERA40. For the majority of the model simulations the tropospheric signal associated to ENSO, even if smaller, is robust as well as the $\Delta Z$ index is significant at $99 \%$ with respect to their standard deviation (the simulations satisfying this are indicated by stars). Only two models (LMDZrepro and UMSLIMCAT) have a non-significant $\Delta Z$ index (dots in Fig. 3 top-right), three models show a $\Delta Z$ index with a significance ranging between $95 \%$ and $99 \%$ (indicated by crosses).

From the above analysis of the $\Delta Z$ index it is implied that the model simulations that do not have a strong enough extratropical ENSO teleconnection pattern in the troposphere are not supposed to have a response in the stratosphere. Indeed, the two models that do not reproduce a significant tropospheric extratropical ENSO signal report a temperature response that is close to zero, or slightly negative (Fig. 3 topright). The rest of the model simulations (the majority) are in good agreement with ERA40, in the sense that they are clustered in the region of positive $\Delta T$ index and larger than 2-standard deviation ERA40 $\Delta Z$ index. Their positive temperature response in the stratosphere (evidenced also by the histogram) is however characterized by a large spread. This spread is therefore due to the modeled stratospheric internal variability. 

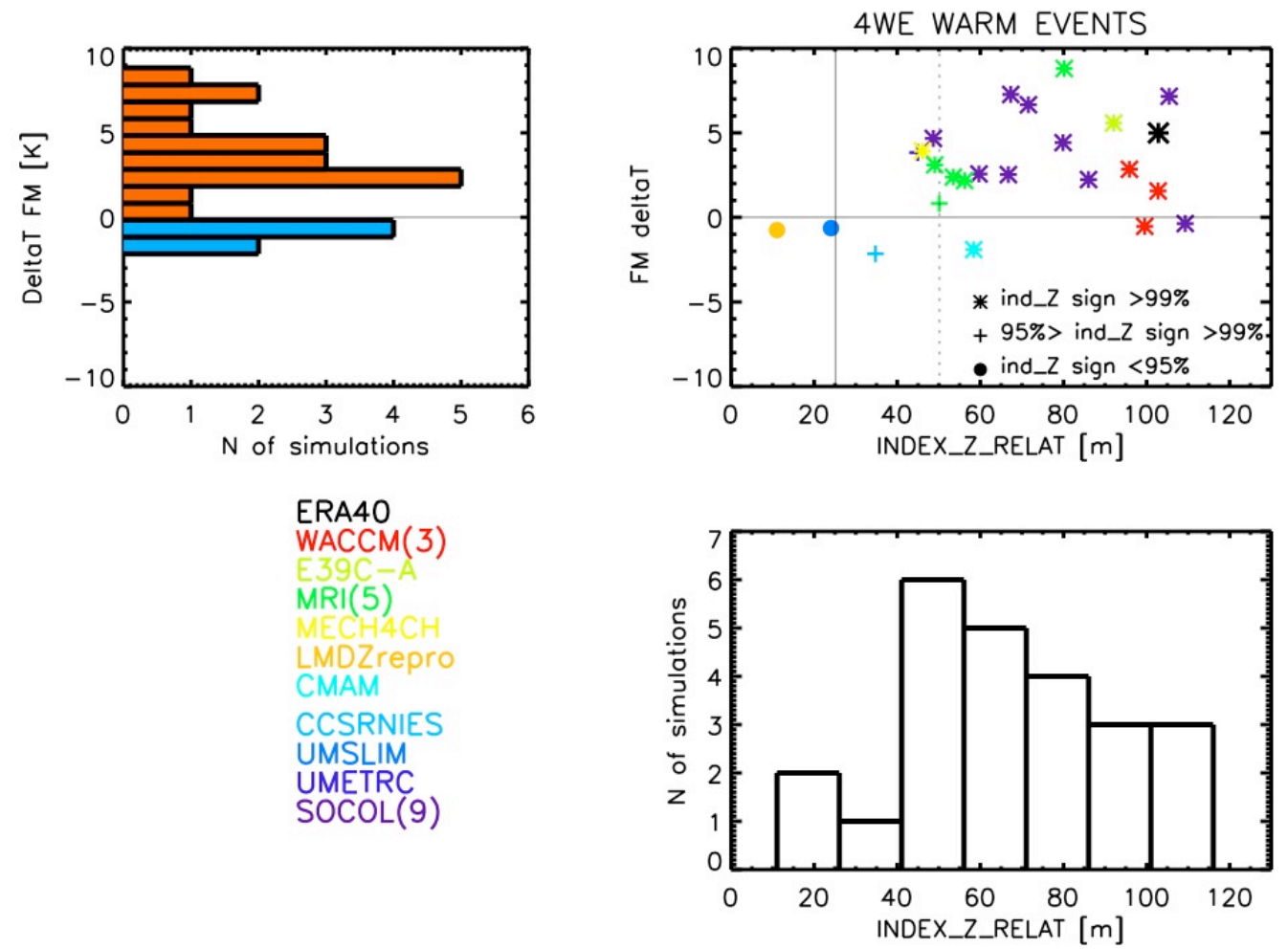

Fig. 3. (Top-left) Histogram of the temperature (K) anomaly of Fig. 2 ( $4 \mathrm{WE}=4$ warm events), averaged over February and March ( $\Delta T$ FM) for 24 models; red/blue bars indicate the number of model simulations with positive/negative temperature response. (Top-right) scatter plot for each model (listed in Table 1) and ERA40 of the temperature $(\mathrm{K})$ anomaly of Fig. 2, averaged over February and March $(\Delta T$ index), versus the $\Delta Z$ index (m; index_z_relat) at $500 \mathrm{hPa}$; (Bottom-right) histogram of the $\Delta Z$ index (m) at $500 \mathrm{hPa}$ for the models. The simulations with a $\Delta Z$ index significant at $99 \%$ and $95 \%$ are represented by stars and crosses, respectively; the simulations with a non-significant $\Delta Z$ index are shown by dots. 1-standard deviation and 2-standard deviations for the $\Delta Z$ index of ERA40 are shown as the vertical continuous and dotted lines, respectively.

Another important result of Fig. 3 is that differences among the simulations in the $\Delta Z$ index are almost twice larger than the differences within the multiple realization runs of a model (see the $\Delta Z$ index range for WACCM, MRI, and SOCOL). As discussed above, an explanation of this result is that the tropospheric ENSO teleconnection is substantially different for some of the models. Although also the spread in this index among the model simulations with a significant $\Delta Z$ index can be related to the variability of the ENSO extra-tropical tropospheric teleconnections, for the models with an insignificant index it should be mainly related to model formulation. On the other hand, the comparable spread $(-2 \mathrm{~K}$ to $9 \mathrm{~K})$ in the $\Delta T$ index among all the model simulations is indicative of the modeled stratospheric internal variability, and suggests that even with a similar ENSO teleconnection in the troposphere (see for example WACCM), there is variability in the lower stratospheric temperature response.

\section{Ozone}

The impact of ENSO on the column ozone distribution is illustrated in Fig. 4 for the models, the NIWA dataset and for the mean of all model simulations, at polar latitudes $\left(70^{\circ} \mathrm{N}-\right.$ $90^{\circ} \mathrm{N}$ average, top $)$ and in the Tropics $\left(15^{\circ} \mathrm{S}-15^{\circ} \mathrm{N}\right.$ average, bottom).

In the polar region, the NIWA column ozone anomaly is negative from October to January and positive in February, March and April. The NIWA total ozone positive anomaly is largest in February ( 20 DU). The model responses show a large spread, especially in January, February and March. The column ozone anomaly in the mean of all model simulations is positive from January to April and reaches $\sim 10 \mathrm{DU}$ in March (not significant). In the tropical regions (Fig. 4, bottom), negative ozone anomalies are observed throughout the whole winter season. The largest negative anomalies are again obtained for the same months: in February ( $-7 \mathrm{DU})$ for NIWA and in March (-6DU, significant at 95\%) for the mean of all model simulations. Figure 4 demonstrates that an increase of the column ozone in the Arctic (top) is 

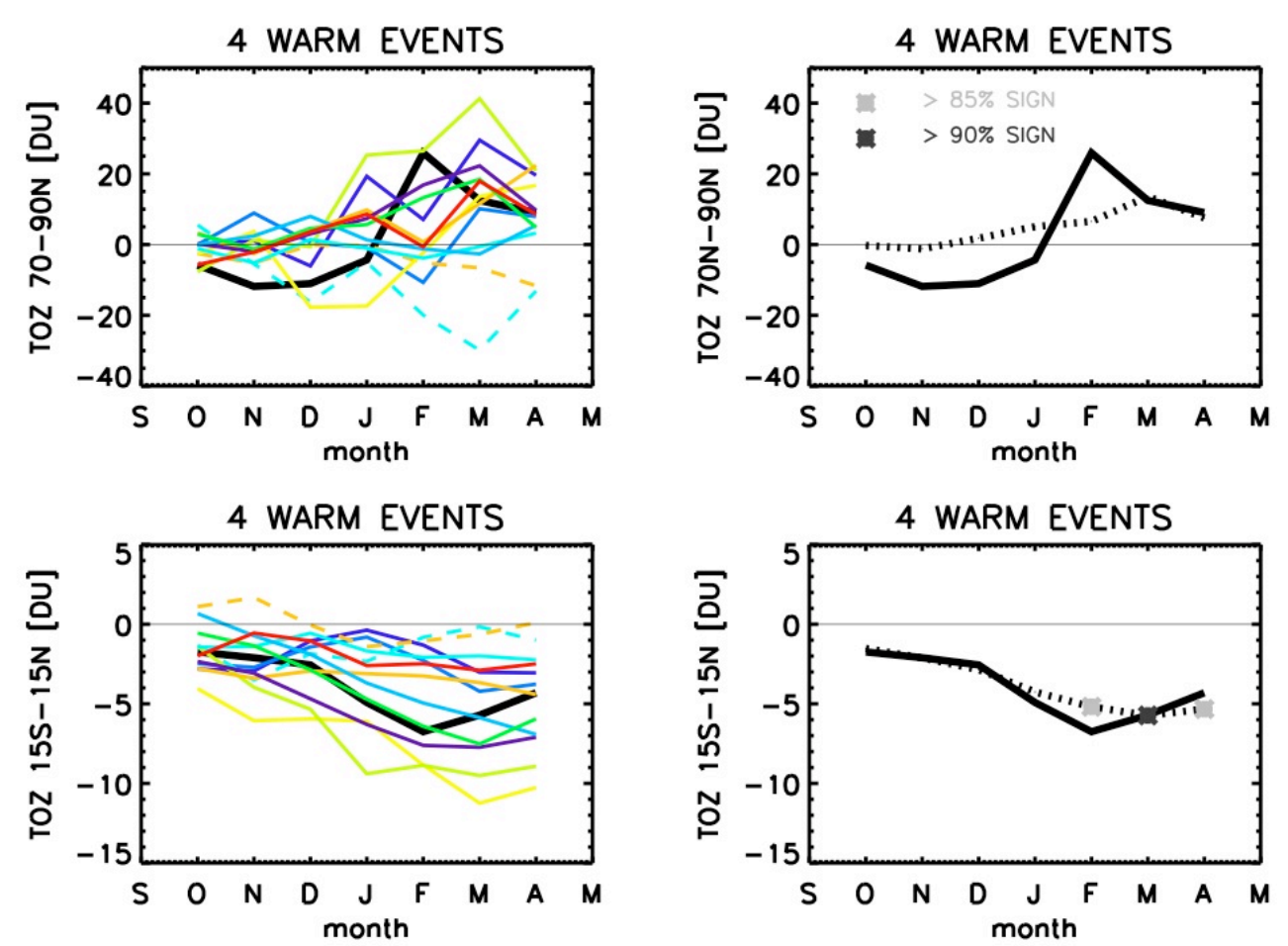

Fig. 4. Monthly zonal mean column ozone (DU) ENSO anomalies from October to April, averaged over the polar cap ( $\left.70^{\circ} \mathrm{N}-90^{\circ} \mathrm{N}\right)$ (topleft) and between $\left(15^{\circ} \mathrm{N}-15^{\circ} \mathrm{S}\right)$ (bottom-left), for each model and for NIWA (black curve). The color code for the models is the same as Fig. 2. One curve per model is plotted, i.e. the anomaly has been averaged over the ensemble members, when available. (Right) the mean of all simulations (black dots) and NIWA (black curve). Superimposed are significances at more than 90\% (grey stars) and 95\% (black stars) for the mean of all simulations.

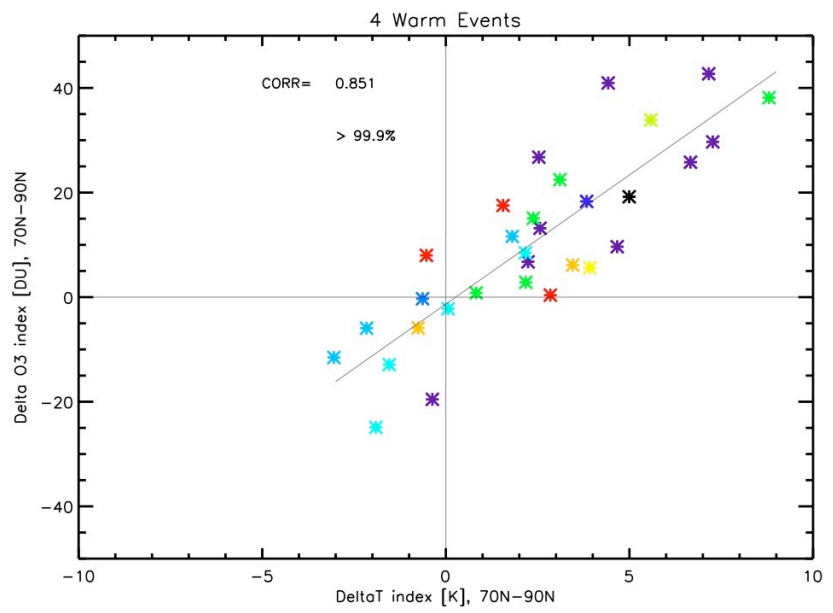

Fig. 5. Scatter plot of the $\Delta \mathrm{O}_{3}$ index (column ozone ENSO anomaly, DU, of Fig. 4 top-left averaged over February and March) versus the $\Delta T$ index (temperature anomaly, $\mathrm{K}$, of Fig. 2, averaged over February and March). Black star: the NIWA $\Delta \mathrm{O}_{3}$ index (DU) versus the ERA40 $\Delta T$ index $(\mathrm{K})$. accompanied by a coherent column ozone decrease at tropical latitudes (bottom).

The accumulation of ozone at high latitudes is indicative of stronger diabatic descent during ENSO in that region, consistent with a warmer polar lower stratosphere (Fig. 2) and an increased Brewer Dobson circulation. The column ozone decrease in the tropics is consistent with increased ascent in the lower stratosphere circulation and, again, increased Brewer-Dobson circulation. As for the temperature, the column ozone anomaly across the models at high latitudes is highly variable showing a large spread in the model responses. In the tropics, the response across the models is consistent and quite robust (Fig. 4, bottom-left and the significance in the bottom-right). Note however that in the tropics the column ozone is also directly affected by ENSO, because during ENSO the warmer sea surface temperatures lead to a warmer troposphere and a higher tropopause throughout most of the tropics. The higher tropopause in turn implies a decrease of the tropical column ozone (Shiotani, 1992; Steinbrecth et al., 2006). The response in the tropical lower stratosphere can also be directly related to local tropical wave forcing (Deckert and Dameris, 2008) a topic not addressed in the current work. 

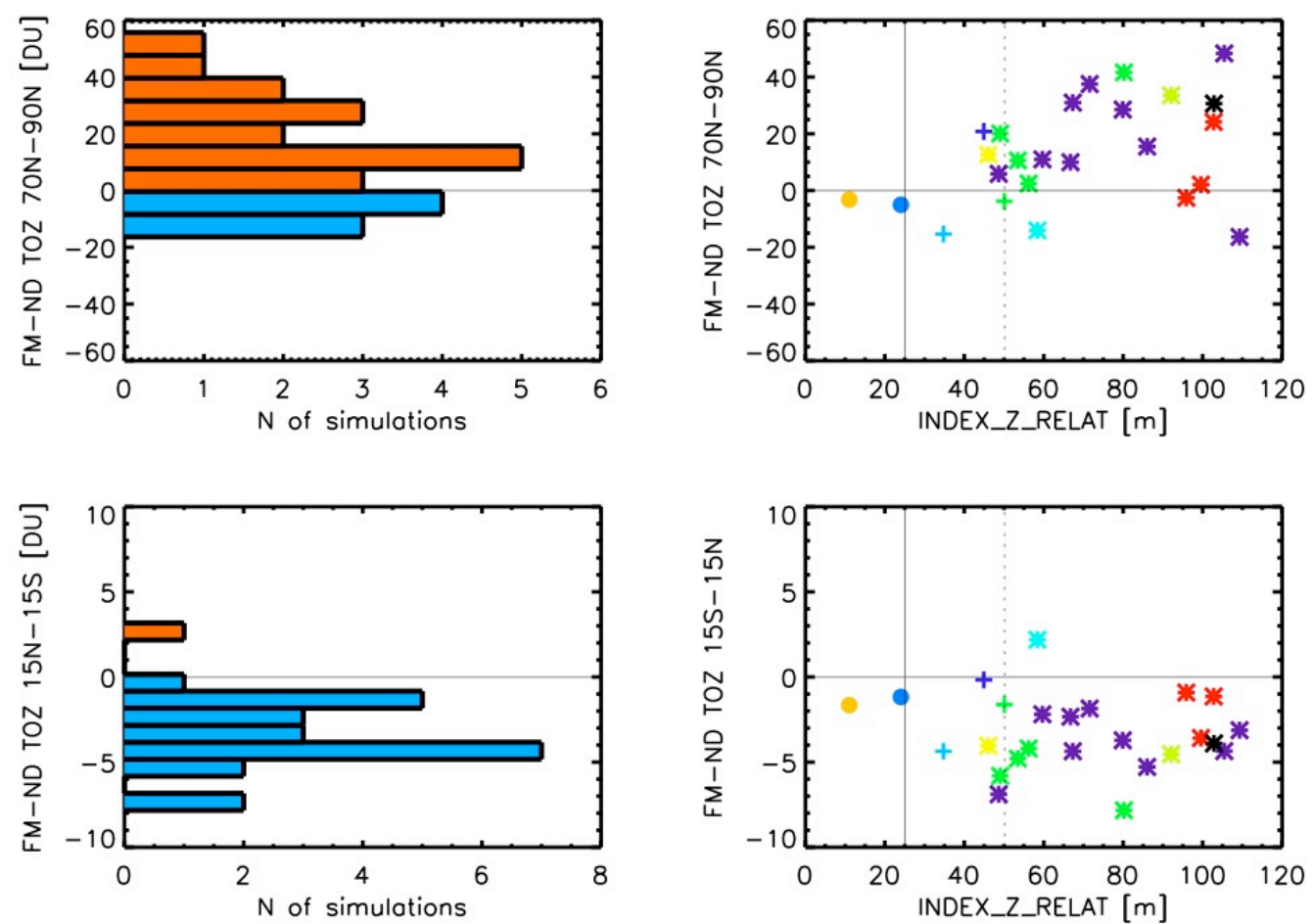

Fig. 6. (Left) Histogram of the $\Delta \mathrm{O}_{3}(\mathrm{FM}-\mathrm{ND})$ index (the column ozone anomaly, DU, average of February and March, minus the NovemberDecember average) for all the models at $70^{\circ} \mathrm{N}-90^{\circ} \mathrm{N}$ (top) and $15^{\circ} \mathrm{N}-15^{\circ} \mathrm{S}$ (bottom); red/blue bars indicate the number of model simulations with positive/negative temperature response. (Right) scatter plot of the $\Delta \mathrm{O}_{3}(\mathrm{FM}-\mathrm{ND})$ index versus the $\Delta Z$ index (m) at $70^{\circ} \mathrm{N}-90^{\circ} \mathrm{N}$ (top) and $15^{\circ} \mathrm{N}-15^{\circ} \mathrm{S}$ (bottom) for all models (in color, coded as in Fig. 3). Black stars represent the NIWA $\Delta \mathrm{O}_{3}(\mathrm{FM}-\mathrm{ND})$ index versus the ERA40 $\Delta Z$ index. The simulations with a $\Delta Z$ index significant at $99 \%$ and $95 \%$ are represented by stars and crosses, respectively; the simulations with a non-significant $\Delta Z$ index are shown by dots. 1-standard deviation and 2-standard deviations for the $\Delta Z$ index of ERA40 are shown as the vertical continuous and dotted lines, respectively.

Figure 5 reports a scatter plot of the $\Delta \mathrm{O}_{3}$ index versus the $\Delta T$ index. This figure shows that the ENSO response in $\Delta \mathrm{O}_{3}$ and $\Delta T$ for the majority of the models is located in the upperright quadrant, in agreement with the signature from observations. Moreover, a clear positive correlation $(0.85$, significant at more than $99.9 \%$ ) between the modeled column ozone and temperature anomalies is found. This relationship is consistent with the one expected from inter-annual variability. Indeed, the slope deduced from Fig. 5 (about $5 \mathrm{DU} / \mathrm{K}$ ) is close to the slope calculated using the ERA40 temperature and NIWA column ozone from the pool of all the individual years (about 5.5 DU/K; not shown). Moreover, Fig. 5 shows that the positive correlation appears also for the 9 realizations from the SOCOL model and possibly the 5 realizations from the MRI model, and that the spread among the models is comparable to the spread among the same-model realizations of either SOCOL or MRI. These results indicate that the cause of the spread in the modeled responses is physical (as opposed to be due to unphysical biases in the models), and it is due to modeled internal variability. The internal stratospheric variability appears to play a dominant role, possibly obscuring differences due to model formulation.
The anomalous wintertime increase of column ozone at high latitudes and decrease at low latitudes is defined as the anomalous tendency of column ozone from the beginning of winter to the end of winter/beginning of spring and is analyzed following Salby and Callaghan (2002) and Fusco and Salby (1999). Figure 6 (left) shows the distribution of the $\Delta \mathrm{O}_{3}$ (FM-ND) index (Sect. 2) at polar (top) and tropical (bottom) latitudes. The distribution of the $\Delta \mathrm{O}_{3}$ (FM-ND) index is clearly negative at tropical latitudes (with 23 simulations reporting a negative index and just one realization with a positive index) whilst it is generally positive (17 models) at high latitudes. In this case, the anomalous wintertime increase of column ozone at high latitudes represents the column ozone dynamical accumulation (i.e. ozone that is transported by anomalous residual circulation) with a negligible contribution of the dynamically-induced chemical effect (i.e. changes in ozone due to changes in photochemistry induced by dynamical changes in temperature), because ENSO years are anomalously warm.

In order to quantify the sensitivity of the anomalous stratospheric ozone accumulation controlled by dynamical variability to the tropospheric forcing in the North Pacific region 
during ENSO, Fig. 6 (right) shows the scatter plot of the wintertime dynamical ozone accumulation during ENSO (the $\Delta \mathrm{O}_{3}$ (FM-ND) index) together with the $\Delta Z$ index, as already done for the anomalous temperature in Fig. 3. Figure 6 shows that model simulations that are in good agreement with ERA40 (modeled $\Delta Z$ index larger than 2-standard deviations ERA40 $\Delta Z$ index) simulate a dynamically accumulated ozone during ENSO at polar latitudes and a decrease at low latitudes, reflecting enhanced stratospheric transport, as expected from previous analysis of Figs. 3 and 5. In particular, as in Fig. 3, the only two models with a non-significant (at 95\%) $\Delta Z$ index (dots in Fig. 6) report a response in ozone at both latitudinal bands that is close to zero (as for temperatures in Fig. 3).

The ozone sensitivity to the strength of the ENSO forcing into the troposphere deduced from Fig. 6 shows that an increasing of the tropospheric forcing in the North Pacific region during ENSO of about 2-3 standard deviations implies a modeled wintertime ozone accumulation of about 15$25 \mathrm{DU}$ (and a simultaneous reduction ranging between -2 and $-5 \mathrm{DU}$ in the Tropics). These quantities for the observational datasets are $\sim 30 \mathrm{DU}$ in the Arctic ( $-5 \mathrm{DU}$ in the Tropics), with an enhanced tropospheric ENSO forcing of about 4 standard deviations. Therefore, the modeled ozone sensitivity to the strength of the tropospheric ENSO forcing is in good agreement with the observational datasets.

\section{Summary and conclusions}

A systematic CCM inter-comparison of the stratospheric temperature and ozone response to ENSO for the Northern winter is reported. The model simulations considered here are those used for the CCMVal-1 activity (presented and discussed in Eyring et al., 2006), of which many contributed to the last ozone assessment (WMO/UNEP, 2007). The main results are summarized here:

1. In the lower stratosphere, the mean of all model simulations reports a warming of the polar vortex during strong ENSO events: The February-March temperature anomaly in the lower stratosphere is positive, significant and of the order of $2 \mathrm{~K}$ for the mean of all model simulations. The response to ENSO obtained from the individual simulations is however highly variable, because of the large internal atmospheric variability and possibly also because of differences in model formulations. The mean anomaly derived from the model simulations is consistent with but smaller $(\sim 2 \mathrm{~K})$ than the estimate from the SSU temperature $(\sim 4 \mathrm{~K})$ and from ERA40 $(\sim 6 \mathrm{~K})$ in the lower stratosphere.

2. The warming found in the mean of all model simulations in the polar lower stratosphere is associated with an increase of column ozone north of $70^{\circ} \mathrm{N}$ : The column ozone ENSO anomaly in the mean of all model simulations is positive and of the order of $10 \mathrm{DU}$ in March. The dynamical increase of the column ozone in the Arctic during ENSO is accompanied by coherent column ozone decrease in the Tropics (7 DU). The modeled anomalies are in very good agreement with those derived by the NIWA column ozone in the Tropics and consistent but about one half of the anomalies found with NIWA in the Arctic ( 20 DU in February).

3. The $\Delta Z$ index represents a measure of the eastward elongation of the north-west Pacific trough during warm ENSO years. As discussed in Manzini et al. (2006), this structure is persistent in time and may enhance the tropospheric forcing of upward propagating planetary wave one (see also the Appendix A). Once the planetary wave one is enhanced also in the stratosphere, it can affect the zonal mean flow (by wave-mean flow interaction) and give rise to large-scale effects. The analysis of the $\Delta Z$ index reveals that the temperature and ozone response in the lower stratosphere depend on the representation of the tropospheric ENSO teleconnection: For the most of the model simulations that have a significant ENSO teleconnection pattern in the troposphere, the Arctic lower stratosphere is warmer, and the response in ozone is characterized by, an increased ozone dynamical accumulation in the polar latitudes and a decrease at tropical latitudes, consistent with increased circulation in the stratosphere. Conversely, the model simulations that do not have a strong enough extra-tropical ENSO teleconnection pattern in the troposphere (and that therefore are not supposed to have a response in the stratosphere) show indeed a stratospheric signal close to zero.

4. Even if the modeled ozone anomalies are smaller that the anomalies found with NIWA in the Arctic, the modeled ozone sensitivity to the strength of the tropospheric ENSO forcing is in good agreement with the observational datasets: from about 15 to $25 \mathrm{DU}$ in the Arctic (from -2 to $-5 \mathrm{DU}$ in the Tropics) for an increase of the ENSO forcing of about 2-3 standard deviations in the models; $\sim 30 \mathrm{DU}$ in the Arctic ( $-5 \mathrm{DU}$ in the Tropics) for an increase of about 4 standard deviations in the observations.

5. The role of modeled internal variability in the polar stratospheric ENSO response has been deduced by the spread in the temperature and ozone ENSO anomalies for the models that provided more than one realization of the 20-year period considered. We have found that the spread of the $\Delta Z$ index among the models tends to be larger than the spread within the realizations obtained by one model (MRI, SOCOL, WACCM). In particular, for the SOCOL model, for which there are 9 realizations, the spread between its realizations is about half the total spread. We also notice that only two 
models (LMDZrepro and UMSLIMCAT) report a $\Delta Z$ index that is non-significant and is below one standard deviation $(\sim 25 \mathrm{~m})$ of the stationary eddies of ERA40, suggesting that the tropospheric ENSO teleconnection for these models is underestimated, because of model biases in the representation of tropospheric processes. These results imply that tropospheric variability and differences in representing ENSO teleconnection in the troposphere, due to differences in model formulations, play a substantial role in the stratospheric response to ENSO.

To summarize, our systematic intercomparison of the sensitivity of the response to ENSO in the stratosphere for CCMs included in the CCMVal-1 activity is in agreement with previous analysis based on observational datasets (Brönnimann, 2004), the SOCOL CCM (e.g. Fischer et al., 2008; Brönnimann et al., 2006) and other modeling studies (e. g. Sassi et al., 2004; Manzini et al., 2006). Namely, also the mean of all simulations from the pool of models considered here display a polar warming and increased column ozone during ENSO years. Differently from the mentioned works in this analysis the ENSO signal in the lower stratosphere is considered to be non linear, through the use of the composite technique (following Manzini et al., 2006 and Hoerling 1997).

The reported modeled and observed warming in FM lower stratosphere and increase (decrease) in total column ozone at high (low) latitudes, is consistent with increased residual circulation during ENSO. Given the spread in the temperature and the ozone responses to ENSO, within the pool of available simulations, the strength of this increase is presumably also highly variable. The positive correlation (significant at more than 99\%) and the slope found between the ENSO anomaly in temperature and column ozone indicates that interannual variability is the main driver for the $\Delta T$, $\Delta \mathrm{O}_{3}$ covariance, hence interannual variability explains the spread in response to ENSO.

The responses in the lower stratospheric temperature and in column ozone are highly variable indicating that the large internal stratospheric variability in the models plays a major role in determining these responses. Nevertheless, by quantifying the tropospheric stationary eddy enhancement during ENSO and its variability across the model simulations, we have shown that the tropospheric ENSO teleconnections are important in explaining the range of responses in the lower stratospheric temperature and in column ozone. In fact, our analysis suggests a strong link between the dynamical ENSO external forcing of the stratosphere and the strength of the response in the stratosphere. This result is therefore the most promising for being used to differentiate between the role of internal variability and model formulation in a larger pool of realizations and models and it highlights that tropospheric modeling (specifically the parameterizations of the processes related to diabatic heating and the modeled mean
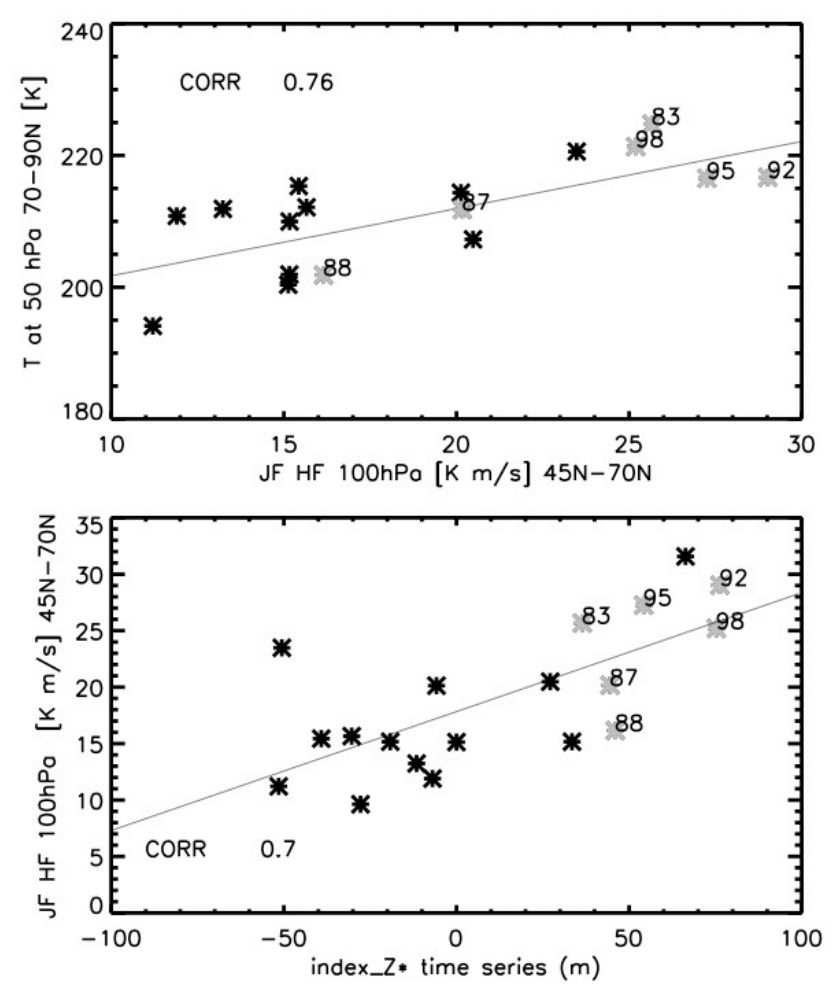

Fig. A1. Scatter plot of (top) the February-March temperature at $50 \mathrm{hPa}$ averaged between $70^{\circ}-90^{\circ} \mathrm{N}$ and the January-February eddy heat flux anomalies at $100 \mathrm{hPa}$ averaged between $45^{\circ} \mathrm{N}-$ $75^{\circ} \mathrm{N}$; (bottom) the January-February heat flux anomaly at $100 \mathrm{hPa}$ averaged between $45^{\circ} \mathrm{N}-75^{\circ} \mathrm{N}$ and the new $\Delta Z^{*}$ index. Grey stars represent the ENSO years. Data from one simulation of the MRI model.

state) is important when attempting to accurately simulate the stratospheric response to ENSO forcing in Chemistry Climate Models.

\section{Appendix A}

The link between the $\Delta Z$ index, defined in Sect. 2.3 and discussed in Sect. 4, and the eddy heat flux at $100 \mathrm{hPa}$ is detailed here.

Figure A1 shows (top) the correlation between the February-March polar cap averaged temperature at $50 \mathrm{hPa}$ and the January-February heat flux anomaly at $100 \mathrm{hPa}$ averaged between $45^{\circ}-75^{\circ} \mathrm{N}$, for each single year of one of the MRI simulations (as an example); and (bottom) the correlation between the January-February heat flux anomaly at $100 \mathrm{hPa}$ averaged between $45^{\circ}-75^{\circ} \mathrm{N}$ and a new $\Delta Z^{*}$ index calculated in the following way: at $500 \mathrm{hPa}, 50^{\circ} \mathrm{N}$ and for the $\Delta Z$ index longitude, for each year of the 1980-1999 period, the difference between the DJF averaged stationary eddy geopotential height of that year and its climatology as computed from the NEUTRAL years (NEUTRAL years 
defined in Table 2). This computation implies that the average of $\Delta Z^{*}$ for the 4 warm ENSO years is the $\Delta Z$ index used in Fig. 3. In grey are the signatures for the 4 ENSO events used in Fig. 3 and the two additional ones used in Fig. 2. Figure A1 (top) shows that three events $(1983,1992,1998)$ of the four strongest events lie at the up-right side of this scatter plot: For three of the four largest ENSO events, the temperature and heat flux are grouped together as the strongest ones. Figure A1 (top) therefore supports the notion that that the heat flux is high for warm ENSO. Figure A1 (bottom) shows that there actually appears to be also a linear relationship between the January-February heat flux anomalies at $100 \mathrm{hPa}$ and the $\Delta Z^{*}$ index for the MRI simulation, and that it is in agreement with our expectation: ENSO years are characterized by large heat fluxes and $\Delta Z^{*}$ indices (grey signatures).

Acknowledgements. Chiara Cagnazzo is supported by the Centro Euro-Mediterraneo per i Cambiamenti Climatici. Elisa Manzini acknowledges the support of the EC SCOUT-O3 Integrated Project (505390-GOCE-CT-2004) for part of this work. Natalia Calvo was supported by the Spanish Ministry of Education and Science and the Fulbright Commission in Spain. CCSRNIES's research has been supported by the Global Environmental Research Fund (GERF) of the Ministry of the Environment (MOE) of Japan (A-071). MRI simulations have been made partly with the MRI supercomputer and partly with the NIES supercomputer. CMAM simulations were supported by the Canadian Foundation for Climate and Atmospheric Sciences and run on the Environment Canada Supercomputer. We acknowledge the modeling groups for making their simulations available for this analysis, the ChemistryClimate Model Validation Activity (CCMVal) for WCRP's (World Climate Research Programme) SPARC (Stratospheric Processes and their Role in Climate) project for organizing and coordinating the model data analysis activity, and the British Atmospheric Data Center (BADC) for collecting and archiving the CCMVal model output. Chiara Cagnazzo and Elisa Manzini are grateful to Antonio Navarra for useful discussions. We are thankful to John Austin for suggestions and discussions on the manuscript.

Edited by: W. Lahoz

\section{References}

Akiyoshi, H., Zhou, L. B., Yamashita, Y., Sakamoto, K., Yoshiki, M., Nagashima, T., Takahashi, M., Kurokawa, J., Takigawa, M., and Imamura, T.: A CCM simulation of the breakup of the Antarctic polar vortex in the years 1980-2004 under the CCMVal scenarios, J. Geophys. Res., 114, D03103, doi:10.1029/2007JD009261, 2009.

Akiyoshi, H., Sugita, T., Kanzawa, H., and Kawamoto, N.: Ozone perturbations in the Arctic summer lower stratosphere as a reflection of NOx chemistry and planetary scale wave activity, J. Geophys. Res., 109, D03304, doi:10.1029/2003JD003632, 2004.

Austin, J.: A three-dimensional coupled chemistry-climate model simulation of past stratospheric trends, J. Atmos. Sci., 59, 218232, 2002.

Austin, J. and Butchart, N.: Coupled chemistry-climate model simulation for the period 1980 to 2020: Ozone depletion and the start of ozone recovery, Q. J. Roy. Meteorol. Soc., 129, 32253249, 2003.

Austin, J. and Wilson, R. J.: Ensemble simulations of the decline and recovery of stratospheric ozone, J. Geophys. Res., 111, D16314, doi:10.1029/2005JD006907, 2006.

Austin, J., Wilson, R. J., Li, F., and Voemel, H.: Evolution of water vapor concentrations and stratospheric age of air in coupled chemistry- climate model simulations, J. Atmos. Sci., 64, 905921, 2007.

Beagley, S. R., de Grandpre', J., Koshyk, J. N., McFarlane, N. A., and Shepherd, T. G.: Radiative-dynamical climatology of the first-generation Canadian Middle Atmosphere Model, Atmos. Ocean, 35, 293-331, 1997.

Bloom., S., da Silva, A., Dee, D., Bosilovich, M., Chern, J.-D., Pawson, S., Schubert, S., Sienkiewicz, M., Stajner, I., Tan, W.W. and Wu, M.-L.: Documentation and validation of the Goddard Earth Observing System (GEOS) data assimilation system Version 4, in Global Modeling Data Assimilation 104606, Tech. Rep. Ser. 26, NASA Goddard Space Flight Cent., Md., 2005.

Bodeker, G. E., Shiona, H., and Eskes, H.: Indicators of Antarctic ozone depletion, Atmos. Chem. Phys., 5, 2603-2615, 2005, http://www.atmos-chem-phys.net/5/2603/2005/.

Brindley, H. E., Geer, A. J., and Harries, J. E.: Climate variability and trend in SSU radiances: a comparison of model predictions and satellite observations in the middle stratosphere, J. Climate, 12, 3197-321, 1999.

Brönnimann, S., Luterbacher, J., Staehelin, J., Svendby, T. M., Hansen, G., and Svenøe, T.: Extreme climate of the global troposphere and stratosphere 1940-1942 related to El Nino, Nature, 431, 971-974, 2004.

Brönnimann, S., Schraner, M., Müller, B., Fischer, A., Brunner, D., Rozanov, E., and Egorova, T.: The 1986-1989 ENSO cycle in a chemical climate model, Atmos. Chem. Phys., 6, 4669-4685, 2006, http://www.atmos-chem-phys.net/6/4669/2006/.

Cagnazzo, C. and Manzini, E.: Impact of the stratosphere on the winter tropospheric teleconnections between ENSO and the North Atlantic and European Region, J. Climate, 22(5), 12231238, 2009.

Camp, C. D. and Tung, K.-K.: Stratospheric polar warming by ENSO in winter: A statistical study, Geophys. Res. Lett., 34, L04809, doi:10.1029/2006GL028521, 2007.

de Grandpre, J., Beagley, S. R., Fomichev, V. I., Griffioen, E., McConnell, J. C., Medvedev, A. S., and Shepherd, T. G.: Ozone climatology using interactive chemistry: Results from the Canadian Middle Atmosphere Model, J. Geophys. Res., 105, 2647526492, 2000.

Deckert, R. and Dameris, M.: Higher tropical SSTs strengthen the tropical upwelling via deep convection, Geophys. Res. Lett., 35, L10813, doi:10.1029/2008GL033719, 2008.

Egorova, T., Rozanov, E., Zubov, V., Manzini, E., Schmutz, W., and Peter, T.: Chemistry-climate model SOCOL: A validation of the present-day climatology, Atmos. Chem. Phys., 5, 1557-1576, 2005 , http://www.atmos-chem-phys.net/5/1557/2005/.

Eyring, V., Butchart, N., Waugh, D., et al.: Assessment of temperature, trace species, and ozone in chemistry-climate model simulations of the recent past, J. Geophys. Res., 111, D22308, doi:10.1029/2006JD007327, 2006. 
Fioletov, V. E. and Shepherd, T. G.: Seasonal persistence of midlatitude total ozone anomalies, Geophys. Res. Lett., 30, 1417, doi:10.1029/2002GL016739, 2003.

Fischer, A. M., Shindell, D. T., Winter, B., Bourqui, M. S., Faluvegi, G., Rozanov, E., Schraner, M., and Brönnimann, S.: Stratospheric winter climate response to ENSO in three chemistry-climate models, Geophys. Res. Lett., 35, L13819, doi:10.1029/2008GL034289, 2008.

Free, M., and Seidel, D. J.: The observed ENSO temperature signal in the stratosphere, J. Geophys. Res., doi:10.1029/2009JD012420, in press, 2009.

Fusco, A. C. and Salby, M. L.: Interannual variations of total ozone and their relationship to variations of planetary wave activity, J. Climate, 12, 1619-1629, 1999.

Garcia, R. R., Marsh, D. R., Kinnison, D. E., Boville, B. A., and Sassi, F.: Simulation of secular trends in the middle atmosphere, 1950-2003, J. Geophys. Res., 112, D09301, doi:10.1029/2006JD007485, 2007.

Garcia-Herrera, R., Calvo, N., Garcia, R. R., and Giorgetta, M. A.: Propagation of ENSO temperature signals into the middle atmosphere: A comparison of two general circulation models and ERA-40 reanalysis data, J. Geophys. Res., 111, D06101 doi:10.1029/2005JD006061, 2006.

Garfinkel, C. I. and Hartmann, D. L.: Effects of El Nino - Southern Oscillation and the Quasi-Biennial Oscillation on polar temperatures in the stratosphere, J. Geophys. Res., 112, D19112, doi:10.1029/2007JD008481, 2007.

Garny, H., Dameris, M., and Stenke, A.: Impact of prescribed SSTs on climatologies and long-term trends in CCM simulations, Atmos. Chem. Phys., 9, 6017-6031, 2009,

http://www.atmos-chem-phys.net/9/6017/2009/.

Hadjinicolaou, P., Pyle J. A., Chipperfeld, M. P., and Kettleborough, J. A.: Effect of interannual meteorological variability on middle latitude $\mathrm{O}_{3}$, Geophys. Res. Lett., 24, 2993-2996, 1997.

Hamilton, K.: An examination of observed Southern Oscillation effects in the Northern Hemisphere stratosphere, J. Atmos. Sci., 50, 3468-3473, 1993.

Hoerling, M. P., Kumar, A., and Zhong, M.: El Niño, La Niña, and the nonlinearity of their teleconnections, J. Climate, 10, 17691786, 1997.

Kurokawa, J., Akiyoshi, H., Nagashima, T., Masunaga, H., Nakajima, T., Takahashi, M., and Nakane, H.: Effects of atmospheric sphericity on stratospheric chemistry and dynamics over Antarctica, J. Geophys. Res., 110, D21305, doi:10.1029/2005JD005798, 2005.

Kuroda, Y. and Kodera, K.: Variability of the polar-night jet in the northern and southern hemispheres, J. Geophys. Res., 106(D18), 20703-20713, 2001.

Labitzke, K. and van Loon, H.: The Southern Oscillation. Part IX: The influence of volcanic eruptions on the Southern Oscillation in the stratosphere, J. Climate, 2, 1223-1226, 1989.

Lefevre, F., Brasseur, G. P., Folkins, I., Smith, A. K., and Simon, P.: Chemistry of the 1991-1992 stratospheric winter: Three dimensional model simulations, J. Geophys. Res., 99, 8183-8195, 1994.

Manzini, E., Steil, B., Brühl, C., Giorgetta, M. A., and Krüger, K.: A new interactive chemistry-climate model: 2. Sensitivity of the middle atmosphere to ozone depletion and increase in greenhouse gases and implications for recent stratospheric cooling,
J. Geophys. Res., 108(D14), 4429, doi:10.1029/2002JD002977, 2003.

Manzini, E., Giorgetta, M. A., Esch, M., Kornblueh, L., and Roeckner, E.: The influence of sea surface temperatures on the northern winter stratosphere: Ensemble simulations with the MAECHAM5 model, J. Climate, 19, 3863-3881, 2006.

Nash, J. and Edge, P. R.: Temperature changes in the stratosphere and lower mesosphere 1979-1988 inferred from TOVS radiance observations, Adv. Space Res., 9, 333-341, 1989.

Newman, P. A., Nash, E. R., and Rosenfield, J. E.: What controls the temperature of the Arctic stratosphere during the spring?, J. Geophys. Res., 106, 19999-20010, 2001.

Randel, W. J., Wu, F., and Stolarski, R.: Changes in column ozone correlated with the stratospheric EP fux, J. Meteorol. Soc. Japan, 80, 849-862, 2002.

Randel, W. J., Garcia, R. R., Calvo, N., and Marsh, D.: ENSO influence on zonal mean temperature and ozone in the tropical lower stratosphere, Geophys. Res. Lett., 36, L15822, doi:10.1029/2009GL039343, 2009.

Rozanov, E., Schraner, M., Schnadt, C., Egorova, T., Wild, M., Ohmura, A., Zubov, V., Schmutz, W., and Peter, T.: Assessment of the ozone and temperature variability during 1979-1993 with the chemistry-climate model SOCOL, Adv. Space Res., 35(8), 1375-1384, 2005.

Salby, M. L. and Callaghan, P. F.: Interannual Changes of the Stratospheric Circulation: Relationship to Ozone and Tropospheric Structure, J. Climate, 3673-3685, 2002.

Sassi, F., Kinnison, D., Boville, B. A., Garcia, R. R., and Roble. R.: Effect of El Niño-Southern Oscillation on the dynamical, thermal, and chemical structure of the middle atmosphere, J. Geophys. Res., 109, D17108, doi:10.1029/2003JD004434, 2004.

Scinocca, J. F., McFarlane, N. A., Lazare, M., Li, J., and Plummer, D.: Technical Note: The CCCma third generation AGCM and its extension into the middle atmosphere, Atmos. Chem. Phys., 8, 7055-7074, 2008

Shibata, K. and Deushi, M.: Long-term variations and trends in the simulation of the middle atmosphere 1980-2004 by the chemistry-climate model of the Meteorological Research Institute, Ann. Geophys., 26, 1299-1326, 2008a, http://www.ann-geophys.net/26/1299/2008/.

Shibata, K. and Deushi, M.: Simulation of the stratospheric circulation and ozone during the recent past (1980-2004) with the MRI chemistry-climate model, CGER's Supercomputer Monograph Report Vol. 13, National Institute for Environmental Studies, Japan, 154 pp., 2008 b.

Shiotani, M.: Annual, quasi-biennial, and E1 Nino-Southern Oscillation (ENSO) timescale variations in equatorial total ozone, J. Geophys. Res., 97, 7625-7633, 1992.

Spencer, R. W. and Christy, J. R.: Precision Lower Stratospheric Temperature Monitoring with the MSU: Technique, Validation, and Results 1979-1991, J. Climate, 6, 1194-1204, 1993.

Steil, B., Bruehl, C., Manzini, E., Crutzen, P. J., Lelieveld, J., Rasch, P. J., Roeckner, E., and Krueger, K.: A new interactive chemistry-climate model: 1 . Present-day climatology and interannual variability of the middle atmosphere using the model and 9 years of HALOE/UARS data, J. Geophys. Res., 108(D9), 4290, doi:10.1029/2002JD002971, 2003.

Steinbrecht, W., Hassler, B., Brühl, C., Dameris, M., Giorgetta, M. A., Grewe, V., Manzini, E., Matthes, S., Schnadt, C., Steil, 
B., and Winkler, P.: Interannual variation patterns of total ozone and temperature in observations and model simulations, Atmos. Chem. Phys., 6, 349-374, 2006, http://www.atmos-chem-phys.net/6/349/2006/.

Stenke, A., Dameris, M., Grewe, V., and Garny, H.: Implications of Lagrangian transport for simulations with a coupled chemistryclimate model, Atmos. Chem. Phys., 9, 5489-5504, 2009, http://www.atmos-chem-phys.net/9/5489/2009/.

Stolarski, R. S., Douglass, A. R., Steenrod, S. and Pawson, S.: Trends in stratospheric ozone: Lessons learned from a $3 \mathrm{~d}$ chemical transport model, J. Atmos. Sci., 63, 1028-1041, 2006.

Strauss, D. M. and Shukla, J.: Distinguishing between the SSTforced and internal variability in mid latitudes: Analysis of observations and GCM simulations, Q. J. Roy. Meteor. Soc., 126, 2323-2350, 2000.

Struthers, H., Austin, J., Kreher, K., Bodeker, G., Schofield, R., Johnston, P., Shiona, H., and Thomas, A.: Past and future simulations of $\mathrm{NO}_{2}$ from a coupled chemistry-climate model in comparison with observations, Atmos. Chem. Phys., 4, 2227-2239, 2004 ,

http://www.atmos-chem-phys.net/4/2227/2004/.

Tian, W. and Chipperfield, M. P.: A new coupled chemistry - climate model for the stratosphere: The importance of coupling for future $\mathrm{O}_{3}$ - climate predictions, Q. J. Roy. Meteor. Soc., 131, 281-304, 2005.
Taguchi, M. and Hartmann, D. L.: Increased occurrence of stratospheric sudden warmings during El Nino as simulated by WACCM, J. Climate, 19(3), 324-332, 2006.

Uppala, S., Kallberg, P. W., Simmons, A. J., et al.: ERA-40: ECMWF 45-year reanalysis of the global atmosphere and surface conditions 1957-2002: ECMWF Newsletter, Vol. 101, ECMWF, Reading, United Kingdom, 2-21, 2004.

Uppala, S., Kallberg, P. , Hernandez, A., et al.: The ERA-40 reanalysis, Q. J. Roy. Meteor. Soc., 131, 2961-3211, 2005.

Van Loon, H. and Labitzke, K.: The Southern Oscillation. Part V: The anomalies in the lower stratosphere of the Northern Hemisphere in winter and a comparison with the quasi-biennial oscillation, Mon. Weather Rev., 115, 357-369, 1987.

Weber, M., Dhomse, S., Wittrock, F., Richter, A., Sinnhuber, B.M., and Burrows, J. P.: Dynamical control of NH and SH winter/spring total ozone from GOME observations in 1995-2002, Geophys. Res. Lett., 30(11), 1583, doi:10.1029/2002GL016799, 2003.

World Meteorological Organization/United Nations Environment Programme (WMO/UNEP), Scientific Assessment of Ozone Depletion: 2006, Rep. 50, World Meteorol. Org., Global Ozone Res. and Monit. Proj., Geneva, Switzerland, 2007. 